\title{
The Concept of "Principle" As an Element of Law
}

\author{
Irina A. Aleshkova
}

Institute of Scientific Information of Social Sciences of the Russian Academy of

Sciences, Moscow, Russia

\begin{abstract}
The article is devoted to the characterization of the concept "principle" in jurisprudence. The main approaches associated with the specifics of the expression of the concept "principle" in law (structural and semantic) are identified and analyzed. It is explained that the content of the concept's "principle" can be replenished with new characteristics, in connection with which there is a need for new forms of their legal verbalization. In the context of law, the understanding of principles is identified with moral values. Among them are individual freedom, conscientiousness, honesty, truthfulness, obedience to the law, love for the Motherland, disinterestedness, tolerance, rejection of violence, theft, slander and envy, kindness and mercy, loyalty to the word, respect for elders, respect for honest work, etc. Attention is drawn to the metaphysical nature of the principles in law, which is expressed, firstly, in the fact that principles in law are a complex multifaceted phenomenon of the synthesis of human consciousness and social practice, in fact, the first reason for the emergence of the norms of constitutional law; secondly, in the fact that they are not formally subject to change in time, they either exist or not, while their content evolves in time and space; thirdly.
\end{abstract}

Keywords---concept, constitutional taxonomy, culture, principle, rule.

\section{Introduction}

The principles of constitutional law, being regulators of social relations, have their own system, consisting of hierarchically interconnected, internally agreed concepts - principles. In order to reveal the characteristic features of the concept of "principle", let us consider the features of the evolution of its understanding and application in legal terminology and law. The term "principle" is one of the traditional, frequently used words in legal terminology, through which the primary substance is denoted. Its content includes one or more related meanings. It is traditional to understand the term "principle" as a basic position, prerequisite

Linguistics and Culture Review (c) 2021.

Corresponding author: Aleshkova, I. A.; Email: ialeshkova@mail.ru

Manuscript submitted: 27 August 2021, Manuscript revised: 09 Oct 2021, Accepted for publication: 18 Nov 2021

1586 
or maxim; in an objective sense, he acted as a starting point, a fundamental principle, the very first thing in being (Weber, 1983; Lai \& Zhang, 2009).

In jurisprudence, the concept principle is taken into account based on the approaches formed in linguistics. As a structural unit of the language, the word "principle" comes from the Latin "princeps" and in etymology is considered as a synonym for the word "arche", respectively, it is defined as the beginning, the base, the primary indication, which must be guided to achieve the desired results (Babkin \& Shedetsov, 1994). The term "principle" is defined as an idea, basic position, position, dogma, canon, beginning, thesis, prescription, norm, dictum, basic rule of behavior, maxim (Dal, 1955; Efremova, 2000). It is necessary to pay attention to the fact that when characterizing the principles of Dal (1955), used the concept of "moral principles".

It should also be noted that the principle is often used as a logical element, since it is perceived as a true statement, self-evident and does not require other evidence (Blundeville, 1617). It should also be noted that the term "principle" has several representative words. Highlight the principles governing behavior; principles that determine the basis for the organization and functioning of social institutions, as well as the principles of interaction (Tarde, 1902). In general, it can be noted that the term "principle" is actively used by scientists in many fields (Welty \& Guarino, 2001; Lavine \& Carlson, 1991).

\section{Method}

The comprehension of the processed theoretical sources was carried out on the basis of general scientific research methods, general logical techniques (analysis, synthesis, generalization) were applied with the help of which the characteristic features of the concepts "principle" used in jurisprudence were revealed analytical procedures, considered using a descriptive method. In the research process, we use a comprehensive concept analysis method that helps to draw a conclusion about the metaphysical nature of the concept "principle". Among the private scientific methods, the formal legal method was used (Martin \& Siehl, 1983; Cooper, 2000).

\section{Results and Discussion}

The word principle as a linguistic unit has its own characteristics and characteristics. The form of its expression can be both oral and written (sign), and the variety of types is due to the scope of its use. In the modern period, the word "principle" is also actively used. It is often used as a statement, as a maxim, and is also used to form a conceptual system, where it is necessary to assume the existence of some primary or initial concepts, from which everything else develops (Narutto, 2018; Titova, 2021; Pevtsova, 2021). The emergence of written sources led to the transformation of the oral linguistic representation of the concept "principle" into a written form of its fixation, which for centuries did not change in linguistic representation directly with a person: his consciousness, thinking, as well as the development of culture and society (society). In the process of intercultural communication, the term "principle" actively penetrated into the 
circulation of many languages of the world and became an established and socially determined expression (Schmidt, 2006; Djulbegovic et al., 2000).

In the scientific literature, attention is drawn to the fact that "often the same concept" principle "can be conveyed by various linguistic means: a word, a phrase, a sentence, a number of synonymous words; linguistic means are necessary not for existence, but for communicating the conceptual meaning of the word "principle"; the richness of the content of an individual concept can be revealed only with the help of a set of language means, each of which can reveal only a part of it; the concept "principle" defines the general in the content of linguistic units" (Kozko, 2012). In jurisprudence, principles are considered as the basic part of the structure and models of building relationships between a person (citizen), civil society and the state (Licht et al., 2007; Haggard \& Tiede, 2011).

Culture, that is, human activity in its most diverse manifestations, has a significant impact on the development of the concept of "principle". Principles as part of culture are a set of stable imperative requirements formed as a result of the generalization of the rational experience of relationships. As Karasik (2005), linguacultural and linguo-cognitive approaches to understanding the concept are not mutually exclusive: "the concept as a mental formation in the consciousness of the individual is an outlet to the concept sphere of society, that is, ultimately to culture, and the concept as a unit of culture is the fixation of collective experience, which becomes the property of the individual. In other words, these approaches differ in vectors in relation to the individual: the linguo-cognitive concept is the direction from individual consciousness to culture, and the linguacultural concept is the direction from culture to individual consciousness (Karasik, 2005).

Thus, a system of principles is formed, through which the transfer of especially significant information is carried out. The principle as a result of cognitive (cognitive) activity has a relatively ordered internal structure, acts as a mental or linguistic formation that carries complex information obtained as a result of generalizing the rational experience of interaction in society. In other words, the principle can be characterized as a prerequisite for rational (reasonable) action or behavior. Summarizing the above, it should be noted that a principle is a concept that has content, on the basis of which something is asserted, established or located, acts and is organized, functions or is created. The principle acts as the fundamental principle of everything and encourages concrete actions (Suardiana, 2016; Al-Sofi \& Abouabdulqader, 2020).

Principles in jurisprudence define a universally valid prescription that expresses a duty. In legal terminology, the principle is the dominant factor necessary to determine the contours of legal modes and is a significant component in legal regulations. So, for example, the form of expression of the concepts "the principle of inviolability", "the principle of independence" and "the principle of unity" over time received only a certain concretization, but their significance has not changed over the centuries, respectively, this fact makes it possible to single out such a sign of principles in law as sustainability. They are observable principles, although not always objectified. In law (given its primary expression in the form of 
custom), the principle appears as a natural and self-organizing element (Kalynychenko et al., 2021; Baranov et al., 2021).

The variability of the syntactic compatibility of the word principle with the norms of law insignificantly affects the semantic features of them as linguistic units, and logical semantics allows principles as concepts to have stability of expression. However, this circumstance, in view of changes in social and other conditions of life in the process of development of state and law, leads to an adjustment of the content of some principles used in legal terminology, which, in turn, manifests itself in linguistic changes: the content of the principle will expand its lexical meaning, there is a tendency to the collapse of polysemy, new syntactic units are formed. A significant impetus for the development of principles as a phenomenon in legal terminology used in various areas of legal regulation was that principles as a category were not only included in the conceptual apparatus of most scientists and practitioners and became the basis of many scientific works, but were also defined as an element in legislation (Vressick-Chilborn \& Rachman, 2020; Suwija et al., 2019).

The source of the emergence and modernization of principles as concepts in legal terminology is culture, knowledge and legal technique. "In the course of communication, the concept of "principle" in legal terminology can receive both verbal and non-verbal expression. Accordingly, the forms of expression of the concept "principle" in law are different. There are principles that are expressed in a single word; are part of phraseological combinations and are designed in the form of a stable combination of words, and those that find their expression in phrases and sentences. Considering that the term concept is defined, on the one hand, as a clot of culture in the mind of a person, on the other hand, the concept is that through which a person himself enters the culture, and in some cases affects it Nikishina et al. (2002), it should be noted that the principles significantly influence the formation of legal culture and legal education (Pevtsova, 2021).

In jurisprudence, the term "principle" has become a prerequisite for the formation of many lexico-syntactic units: the principle of law, legal principle, legal principle, generally recognized legal principle, the principle of a civilized society, etc. Principles in legal terminology are used to determine what they adhere to, what they proceed from, what actions and decisions are coordinated with, what is formed and approved, and something is created. At the same time, their mental perception by the subject of law and his conviction in their truth as legal concepts is also of great importance. Principles, as legal concepts, basically determine the possible and what should be, value attitudes and mandatory imperatives acting as prescriptions describing the most significant elements of legal regulation in a hierarchically organized system of law. This, in particular, explains their relevance as regulators that determine the limits of limiting human rights (Umnova-Koniukhova, 2020; Kolosova, 2021; Bencrid \& Lezier, 2021).

Legal terminology is in constant flux and change. In this regard, in the process of its existence, the concept "principle" is able to lose touch with some linguistic units that previously served for its expression, and attract new ones. The variability of concepts in law is associated, first of all, with the fact that 
lawmaking and law enforcement are constantly changing, there is always a search for optimal ways in the maelstrom of legal events, which causes the need for forecasting and, as a result, processing of legal information (Tikhomirov, 2019; Umnova-Konyukhova, 2021). Accordingly, on the one hand, the main unit for storing socially significant information should be flexible and mobile enough to keep up with all changes and easily respond to them; on the other hand, the essential core (central part) of the structure of the principle must be unshakable and ensure the expectation of the implementation of legal prescriptions that are aimed at preserving and ensuring guarantees of those values that have formed within a particular culture.

Over time, the content of the concepts "principle" can be replenished with new characteristics, in connection with which there is a need for new forms of their legal verbalization, which, in turn, causes the emergence of a secondary representation in the language, for example, the formation of derivative concepts on the basis of already existing ones in the form abstract meanings of principles (Likhachev, 1993; Tentimishova, 2016). However, the principle as a concept does not lose its unique quality - stability, which presupposes its constancy. In the context of law, the understanding of principles is identified with moral values. Among them are individual freedom, conscientiousness, honesty, truthfulness, obedience to the law, love for the Motherland, disinterestedness, tolerance, rejection of violence, theft, slander and envy, kindness and mercy, loyalty to the word, respect for elders, respect for honest work, etc. these principles are currently considered as the basis of the state cultural policy of Russia.

Through such identification, the principle, as an element of the legal system, formed to streamline public relations, is a means of ensuring the preservation of cultural heritage, predictability of legal regulation and the consolidation of civil society. Principles as a phenomenon in legal terminology are legal prescriptions that determine the general requirements for the due (modality of duty). The concept "principle", even without its formal expression, can be objectified and have motivating, categorical, conceptual, figurative (vital) signs in the aggregate, making it possible to reveal the essence, content, concept and definition of the concept "principle" in legal terminology. The motivating signs of the "principle" as a concept are those that served as the basis for naming a certain fragment of legal prescriptions, the more ancient the principle, the more motivating features the concept hiding behind this word" (Shulyatikov, 2015).

Such a conceptual attribute of the concept "principle" as a normative context goes back to motivating, because the normative context of the concept "principle" is characterized by the fact that it includes descriptive statements (referring to real actions of people or actual situations) and prescriptive statements (which describe appropriate actions or situations, expressing ideal variations and which, according to the law (rule, ideal), must certainly take place and, conversely, must not happen; prescribe what actions should be taken, allowed or not allowed to be performed, which situation is mandatory or permissible, and which is prohibited, and determine what should happen under certain conditions). So, for example, the principle of equality concerns the real actions of people, and the principle of prohibition of retroactive effect of the law affects a certain factual situation. They, 
acting as an element of the prescription, express the ideal version of what should be.

It should be noted that the statement of Vlasenko (2020), who draws attention to the fact that "there are as many principles of law in legal science as there are stars in the sky", however, not all of them are formally expressed in the legislation. Principles as concepts in legal terminology should be considered from the standpoint of deontic logic, within which it is possible to reveal the essence and content of principles as regulators of social relations using the modalities of morality, the law of other areas of social interaction of people. Principles as a modal statement in law have deontic operators "obligatory", "permitted", "prohibited". To consider a certain set of statements as a normative context, it is sufficient that at least one of the statements included in it is prescriptive. A set of prescriptive statements that do not include a single descriptive statement is also considered a normative context. Prescriptive statements expressing the latter in logic are called deontic. These include statements with the modalities of continuing, prohibition, permission, conditional obligation (Gusev, 2015).

Thus, it can be noted that the normative context as a sign of the concept "principle" in legal terminology and law is characterized by the fact that, in fact, it makes it possible to define principles as deontic statements. At the same time, it should be noted that the principles are not always formally expressed, but this does not prevent the development of the theory of constitutional taxonomy. As an element of law, certain types of principles are quite fully disclosed by many legal scholars, despite the fact that they do not always have a formal expression. Among the first to express a position on the existence of principles in law, not formally expressed, but presented objectively, were Soviet lawyers (Ostroumov, 1964; Yavich, 1978). In their scientific views, they noted that general legal principles are reflected in the categories of legal consciousness of the main objective laws of the development of the political and legal structure of society, which has an objective character.

The best option is when the objective principle becomes a formally expressed prescription in law. This provides the principle as a concept with greater legal force. So, for example, despite the fact that the formal expression of the concept "principle of humanism" in the Russian Federation, as well as in most countries of the world at the constitutional level, is not noted, but it is objectively expressed in normative legal acts establishing legal responsibility. Thus, despite the fact that the principle in law is not always formally expressed, in some cases it appears as a synthesis of legal information obtained on the basis of the mental level of understanding of legal prescriptions, synthesized from legal practice and doctrine.

Conceptual features are formed in the concept "principle" at a higher level of abstraction, but at the same time much qualitative content is not lost. With the help of the principle, abstractly synthesized regulatory, protective, evaluative and other qualities of legal requirements are fixed, and its abstract form of expression, due to its flexibility, can be transformed and concretized in various forms. So, for example, the principle of equality in the sphere of the exercise of democracy is expressed as the principle of equality of voice in the exercise of democracy; in the 
formation of the social model of the state, it is defined as the principle of social equality; when regulating the legal status of an individual, it is defined as the principle of equality before the law and the court.

Understanding the verbal concept of "principle" depends on context, culture, tradition and many more factors. At the same time, the principle is always perceived as true, that is, the intentional consent of the intellect with the real thing or compliance with it (lat.conformitas seu adaequatio intentionalis intellectus cum re). Given this point, they are often defined as a directive strategy if they prove their usefulness for a particular person over a long period of time. Ross (1968), thus used this criterion to distinguish between directives and norms. Pragmatically minded scholars have noted that the property of truth in law is value. If something is true, then this simultaneously means that it is reliable, and the truth can always be relied on, since it does not change depending on the situation (Alchourrón \& Bulygin, 2002).

Also, in principle, as a concept, the prototypes of reality are summed up, the main, main and essential features of the ideal are highlighted. At the same time, the concept of "principle" can have different content in people of different cultures. In this regard, an interesting statement by I.G. Fichte, for the argumentation of which he used an original heuristic method, according to which any generally accepted principle must be considered true if any of its consequences can be explained and proved. In his works, the author develops the principle of universal agreement, noting that "the state is a society organized according to the principles of law" (Vysheslavtsev, 1914).

The structure of the concept "principle" in jurisprudence includes various elements. On the one hand, the core and the periphery are distinguished in its structure, and this determines its structure. On the other hand, the structure of the concept "principle" contains culturological, volitional and value components. It is the value assessment that is a necessary condition for the formation of the concept (Ivanova, 2003). At the same time, the elements that make up the structure of the principle can have different interactions. The concept of principle used in legal terminology is suitable for many variations. At the same time, among the categorical features of the concept "principle", it is necessary to single out the multiplicity and multiplicity of their action as quantities. In fact, this is a certain predicate, that is, an affirmative expression, which in jurisprudence has a special effect. At the same time, the term "principle" remains a stable element in law.

A number of scholars argue that linguistically ambiguous sentences should be understood as principles. However, in our opinion, the concept of "principle" in jurisprudence is characterized by a "common" perception of it as a significant regulator of social relations. This means that the principle is a certain entity of the first order, that is, of the highest rank. However, it has a number of varieties, in particular, they distinguish - constitutional and generally recognized principles. So, in particular, the generally recognized principles at the global level are the prescriptions concerning the human rights system included in such legal acts as the Declaration of Human and Citizen Rights and the Universal Declaration of Human Rights. This circumstance was due to the unity of views 
and legal interests of the participating States that signed these documents as representatives of their cultures and peoples.

In the designated legal acts, principles, as concepts, appear as concepts with a dense core, which have as their feature obligation and normative context. The content of the same principle in each state and at each historical stage of development is ambiguous in terms of content elements, multifaceted and changes with the development of culture, science and practice. The marked concepts of "principles" as mental formations included in the content of these international legal acts include a value component in their content (for example, universal peace, friendly relations, freedom from fear and want, social progress, brotherhood, tolerance, etc.) and act as regulatory prescriptions that determine and regulate the legal status of an individual.

Accordingly, the methodological basis of the holistic theory of the principles of constitutional law (the theory of legal (constitutional) taxonomy) UmnovaKonyukhova \& Aleshkova (2020), is deontic logic, which made it possible to determine that constitutional law contains prescriptions (principles and norms), which are formally expressed semantically significant legal information (Lopes, 2017). The metaphysical nature of the principles in law, which is expressed, firstly, in the fact that the principles in law are a complex multifaceted phenomenon of the synthesis of human consciousness and social practice, in fact, the first reason for the emergence of the norms of constitutional law; secondly, in the fact that they are not formally subject to change in time, they either exist or not, while their content evolves in time and space; thirdly, in the fact that they have a direct relationship with other social regulators; fourthly, principles as a concept in law are an expression of the natural and original result of the rational evolution of law. These factors allow us to assert that, as concepts, principles in law are integrative and can act as an element of legal terminology, a category of law, a means (tool) that ensures the implementation and development of constitutional law, and can also act as direct regulators of social relations.

\section{Acknowledgments}

I am grateful to two anonymous reviewers for their valuable comments on an earlier version of this article. I also express special thanks to my teacher, Professor I.A. Umnova-Konyukhova for her contribution to my development as a scientist.

\section{References}

Alchourrón, C., \& Bulygin, E. (2002). Introducción a la metodología de las ciencias jurídicas y sociales. $1^{\mathrm{a}}$. Reimpresión. Buenos Aires: Astrea.

Al-Sofi, B. B. M. A., \& Abouabdulqader, H. (2020). Bridging the gap between translation and culture: towards a cultural dimension of translation. International Journal of Linguistics, Literature and Culture, 6(1), 113. https://doi.org/10.21744/ijllc.v6n1.795

Babkin, A. M. \& Shedetsov, V. V. (1994). Dictionary of foreign expressions and words used in the Russian language without translation. St. Petersburg: Peter. 
Baranov, P. P., Mamychev, A. Y., Dremliuga, R. I., \& Miroshnichenko, O. I. (2021). Legal consciousness and legal culture in the era of total digitalization: Theoretical-methodological and legal-technical problems. Linguistics and Culture Review, 5(S3),

https: / / doi.org/ 10.21744/lingcure.v5nS3.1665

Bencried, D., \& Lezière, W. (2021). Restrictions And Values Transformation Of Youth In France During The Pandemic Period: Family, Education, Health. Bulletin of the Moscow State Regional University. Series: Jurisprudence, (2), 39-50.

Blundeville, T. 1617, The Arte of Logick.

Cooper, M. D. (2000). Towards a model of safety culture. Safety science, 36(2), 111-136. https://doi.org/10.1016/S0925-7535(00)00035-7

Dal, V. (1955). Explanatory dictionary of the living great Russian language. URL: http://www. dict, 2000.

Djulbegovic, B., Lacevic, M., Cantor, A., Fields, K. K., Bennett, C. L., Adams, J. R., ... \& Lyman, G. H. (2000). The uncertainty principle and industrysponsored research. The Lancet, 356(9230), 635-638. https://doi.org/10.1016/S0140-6736(00)02605-2

Efremova, T. F. (2000). New dictionary of the Russian language. Explanatoryderivational. Moscow: Russky yazyk.

Gusev, S. S. (2015). Logic. Moscow: Prospect.

Haggard, S., \& Tiede, L. (2011). The rule of law and economic growth: where are we?. World development, 39(5), https://doi.org/10.1016/j.worlddev.2010.10.007

Ivanova, S. V. (2003). Linguoculturological aspect of the study of linguistic units: Doctoral Dissertation. Ufa: Bashkir State University.

Kalynychenko, I. A., Latina, H. O., Kopytina, Y. M., Protsenko, I. I., \& Ivanii, I. V. (2021). Formation of professional-pedagogical culture of future specialists of physical culture and sports specialties. Linguistics and Culture Review, 5(S3), 396-410. https://doi.org/10.21744/lingcure.v5nS3.1540

Karasik, V. I. (2005). Jetnospecificheskie koncepty.[Ethnospecific concepts.]. Vvedenie $v$ kognitivnuju lingvistiku.[Introduction to Cognitive Linguistics]. Kemerovo: Kuzbassvuzizdat, 61-105.

Kolosova, N. M. (2021). Restrictions and Deprivations of Electoral Rights: General and Specific. Bulletin of Moscow Region State University. Series: Jurisprudence, 1, 49-55.

Kozko, N. A. (2012). On the question of the means of linguistic representation of the concept. Philological sciences. Questions of theory and practice, 2(13), 7881.

Lai, H., \& Zhang, D. (2009). Concept lattices of fuzzy contexts: Formal concept analysis vs. rough set theory. International Journal of Approximate Reasoning, 50(5), 695-707. https://doi.org/10.1016/j.ijar.2008.12.002

Lavine, B. K., \& Carlson, D. A. (1991). Taxonomy based on chemical constitution: differentiation of new world from old world helicaverpa moths. Microchemical journal, 43(1), 35-41. https://doi.org/10.1016/0026-265X(91)90034-M

Licht, A. N., Goldschmidt, C., \& Schwartz, S. H. (2007). Culture rules: The foundations of the rule of law and other norms of governance. Journal of comparative economics, 35(4), https://doi.org/10.1016/j.jce.2007.09.001 
Likhachev, D. S. (1993). The concept of the Russian language. Izvestiya RAN SLYa, 1, 3-9.

Lopes, P. M. (2017). The syntax of principles: genericity as a logical distinction between rules and principles. Ratio Juris, 30(4), 471-490.

Martin, J., \& Siehl, C. (1983). Organizational culture and counterculture: An uneasy symbiosis. Organizational dynamics, 12(2), 52-64. https:/ / doi.org/10.1016/0090-2616(83)90033-5

Narutto, S. V. (2018). The supremacy of the Constitution as the basis of the constitutional legal order in Russia. Russian law: education, practice, science, 3(105), 30-35.

Nikishina, I., Krasnykh, V. V., \& Izotov, A. I. (2002). The meaning of concept in cognitive linguistics. Language-Mind-Communication, (21), 5-7.

Ostroumov, G. S. (1964). The ratio of law and political consciousness. Problems of Philosophy, 5, 18-23.

Pevtsova, E. A. (2021). Nurturant Relations as an Object of Legal Regulation in the Modern World (Th eoretical and Legal View). Bulletin of Moscow Region State University. Series: Jurisprudence, 3, 26-38.

Pevtsova, N. S. (2021). Right to Physical Existence: Concepts, Regulation and Interpretation. Bulletin of Moscow Region State University. Series: Jurisprudence, 2, 66-75.

Ross, A. (1968). Directives and norms.

Schmidt, B. (2006). Proof of principle studies. Epilepsy research, 68(1), 48-52. https: / / doi.org/10.1016/.i.eplepsyres.2005.09.019

Shulyatikov, I. S. (2015). The term" concept" in modern linguistics. Bulletin of the Vyatka state humanities university, 12, 98-102.

Suardiana, I. W. (2016). The language power, acculturation model towards urban society of transmigration region: wayang ménak sasak art studies in lombok. International Journal of Linguistics, Literature and Culture, 2(3), 77-86. Retrieved from https://sloap.org/journals/index.php/ijllc/article/view/120

Suwija, N., Suarta, M., Suparsa, N., Alit Geria, A.A.G., Suryasa, W. (2019). Balinese speech system towards speaker social behavior. Humanities \& Social Sciences Reviews, 7(5), 32-40. https://doi.org/10.18510/hssr.2019.754

Tarde, G. (1902). Selection 26. Journal of Political Economy, 11, 146-48.

Tentimishova, A. (2016). The Concept and the Concept Sphere in the Research of Linguistic Scientists. Scientific and Methodological Electronic Journal "Concept, 17, 226-230.

Tikhomirov, Yu. A. (2019). Law: forecasts and risks. Moscow: INFRA-M.

Titova, E. V. (2021). Public participation as constitutional lawful behavior. Constitutional and municipal law, 7, 30-34.

Umnova-Koniukhova, I. (2020). Constitutional Narratives Of Human Rights And Freedoms Restrictions, And Their Judicial Application In Order To Implement Part 3 Of Article 55 Of The Constitution Of The Russian Federation. Bulletin of the MSRU. Series Law, (4).

Umnova-Konyukhova, I. A. (2021). Constitutional futuristic law and constitutional futurology in the XXI century. Moscow: Knorus.

Umnova-Konyukhova, I. A., \& Aleshkova, I. A. (2020). On the issue of constitutional taxonomy. Gosudarstvo i pravo, (1), 32-40.

Vlasenko, N.A. (2020). Competition of the principles of law. Legal technology, 14, 46-54. 
Vressick-Chilborn, S., \& Rachman, M. O. (2020). Syntactic structure, morphology, free morphemes and bound morphemes. Macrolinguistics and Microlinguistics, 1(2), 85-92. Retrieved from https://mami.nyc/index.php/.journal/article/view/8

Vysheslavtsev, B. P. (1914). Ethics Fichte. Fundamentals of law and morality in the system of transcendental philosophy, Moscow, PrintinghouseofA. I. Snegirev, 437.

Weber, S. (1983). A general concept of fuzzy connectives, negations and implications based on t-norms and t-conorms. Fuzzy sets and systems, 11(13), 115-134. https://doi.org/10.1016/S0165-0114(83)80073-6

Welty, C., \& Guarino, N. (2001). Supporting ontological analysis of taxonomic relationships. Data \& knowledge engineering, 39(1), 51-74. https://doi.org/10.1016/S0169-023X(01)00030-1

Yavich, L. S. (1978). Pravo razvitogo sotsialisticheskogo obshchestva (sushchnost'i printsipy)[Law of the Developed Socialist Society (Essence and Principles)]. Moscow, Iuridicheskaia literatura [Legal literature]. 